\title{
QUALIDADE DE VIDA DE PESSOAS COM INSUFICIÊNCIA RENAL CRÔNICA EM TRATAMENTO HEMODIALÍTICO
}

\author{
LIFE QUALITY OF PERSONS UNDERGOING HEMODYALISIS WITH CHRONIC KIDNEY FAILURE \\ CALIDAD DE VIDA DE PERSONAS CON INSUFICIENCIA RENAL CRÓNICA EN TRATAMIENTO \\ CON HEMODIÁLISIS
}

\author{
Denise Maria Guerreiro Vieira da Silva ${ }^{1}$ \\ Rozanea M. Vieira² \\ Zuleica Koschnik ${ }^{3}$ \\ Maristela Azevedo ${ }^{4}$ \\ Sabrina da Silva de Souza ${ }^{5}$
}

\begin{abstract}
RESUMO: Trata-se de uma pesquisa convergente-assistencial que teve como objetivo conhecer os elementos que influenciam a qualidade de vida de pessoas com Insuficiência Renal Crônica, em tratamento hemodialítico. Os dados foram obtidos a partir de uma proposta de educação em saúde, desenvolvida em um grupo de convivência, durante o tratamento hemodialítico. Decorrente do processo de análise foram identificadas quatro categorias que representam os elementos considerados como interferindo na qualidade de vida dessas pessoas: assistência à saúde; processo de aceitação e de enfrentamento da condição de saúde; apoio recebido e esperança de um futuro melhor.Mesmo vivendo com uma doença que tem repercussões importantes no bem-estar físico e no papel social, as pessoas se referiram a uma vida onde existe qualidade, apesar de muitas vezes ser difícil perceber ou conquistar essa qualidade.
\end{abstract}

PALAVRAS-CHAVE: qualidade de vida, doenças crônicas, insuficiência renal crônica

ABSTRACT: This is a convergent-assistance research, which has as its objective the identification of the factors affecting the quality of life of people suffering from Chronic Kidney Failure and who are undergoing hemodyalisis. Data were collected in a health education program, developed for a companionship group, across hemodyalisis sessions. During the analysis, four categories were identified, representing the elements that are considered as causes for the life quality conditions of those people: health assistance; acceptance and coping with the health condition; support received, and hoping for a better future. In spite of living with an illness which has important consequences on the physical well-being and social roles, persons referred to a life where quality can be achieved, although sometimes it may be difficult to perceive or conquer such quality.

KEYWORDS: quality of life; chronic illness; kidney failure, chronic

RESUMEN: Se trata de una investigación convergente-asistencial, cuyo objetivo es conocer los elementos que influyen la calidad de vida de las personas con Insuficiencia Renal Crónica en tratamiento con hemodiálisis. Los datos se obtuvieron a partir de una propuesta de educación para la salud, desarrollada con un grupo de convivencia durante el tratamiento. En consecuencia del proceso de análisis se identificaron cuatro categorías que representan los elementos que interfieren en la calidad de vida de esos enfermos: asistencia a la salud; proceso de aceptación y actitud frente a la condición de salud; apoyo recibido y esperanza de un futuro mejor. Aunque vivan con una enfermedad que les trae repercusiones considerables en el bienestar físico y en lo social, las personas se refirieron a tener una vida con calidad. Aunque muchas veces sea difícil percibir o conquistar esa calidad.

PALAVRAS CLAVE: calidad de vida, enfermedades crónicas, insuficiencia renal crónica

Recebido em 28/06/2002

Aprovado em 24/09/2002

\footnotetext{
1 Doutora em Enfermagem. Professora do Departamento de Enfermagem e do Programa de Pós-Graduação em Enfermagem da UFSC. Coordenadora do NUCRON.

${ }^{2}$ Enfermeira especialista em nefrologia, coordenadora do serviço onde a pesquisa foi realizada. Integrante do NUCRON.

${ }^{3}$ Enfermeira do serviço onde a pesquisa foi realizada. Integrante do NUCRON.

${ }^{4}$ Enfermeira com experiência em unidade de diálise. Integrante do NUCRON.

${ }^{5}$ Aluna do Curso de Graduação em Enfermagem da UFSC. Bolsista de Iniciação Científica (PIBIC/UFSC) do projeto "Grupos de convivência: alternativa para melhoria da qualidade de vida de pessoas em condição crônica de saúde".
} 


\section{INTRODUCÃO}

O aumento da incidência das doenças crônicas entre a população é um fato conhecido e tem suscitado muitas discussões sobre a questão. O cuidado à saúde das pessoas com essas doenças tem sido um grande problema na área da saúde, abrangendo várias dimensões e representando um desafio a ser enfrentado no dia-a-dia, tanto por aqueles que vivenciam a situação quanto para os cuidadores. Viver com a condição crônica de saúde, especificamente a Insuficiência Renal Crônica (IRC) traz uma série de mudanças à vida das pessoas e seus familiares, requerendo enfrentamentos, impondo dificuldades que nem sempre a família ou a equipe de saúde está preparada para contribuir e, principalmente, compreender.

Os avanços tecnológicos permitiram uma evolução na assistência às pessoas com IRC, promovendo resultados clínicos evidentes no seu tratamento. Essas pessoas vêm tendo possibilidade de uma maior estabilidade em seu estado de saúde físico, graças à ampliação do conhecimento em nefrologia. É possivel um controle mais efetivo da IRC, resultante especialmente do desenvolvimento e aperfeiçoamento de drogas e do uso de equipamentos sofisticados, como é o caso da hemodiálise. O Brasil tem acompanhado gradativamente este desenvolvimento, disponibilizando tecnologias mundialmente conhecidas, e a legislação tornou-se mais rigorosa a partir da Portaria do Ministério da Saúde n. 82/2000 (BRASIL, 2000), que prevê garantia de uma diálise livre de riscos para todas as pessoas.

No entanto, não existem suficientes investigações que confirmem que esses tratamentos vêm favorecendo uma melhor qualidade de vida (GERHARDT, 1990). Dentre os estudos que abordam a questão da qualidade de vida de pessoas com IRC, encontramos em vários autores uma perspectiva negativa do viver com a IRC, que inclui ser uma doença estressante (LOK, 1996), afetando a qualidade de vida (GOMES, 1997) e trazendo importantes limitações físicas, psicológicas e sociais (WHITE; GRENYER, 1999, GOMES, 1997, CESARINO; CASAGRANDE, 1998, LIMA; GUALDA, 2000).

Ancorados em nossa concepção de que é possivel ter qualidade de vida mesmo tendo uma doença crônica, acreditamos que há necessidade de obtermos mais informações de como a IRC afeta a qualidade de vida das pessoas e de suas famílias, na sua própria perspectiva, focalizando a experiência subjetiva de viver com essa condição crônica e apesar dela.

Compreendemos o conceito de qualidade de vida como subjetivo, dinâmico, que se modifica no processo de viver. A satisfação com a vida e a sensação de bem-estar pode, muitas vezes, ser um sentimento momentâneo. Porém, acreditamos que o investimento na conquista de uma vida com qualidade, pode ir sendo construida e consolidada, num processo que inclui a reflexão sobre o que é definitório para sua qualidade de vida e o estabelecimento de metas a serem atingidas, tendo como inspiração o desejo de ser feliz
(NORDENFELT, 1994).

A preocupação com a qualidade de vida dos individuos em condição crônica de saúdetem sido constante nos trabalhos desenvolvidos pelo grupo de pesquisa NUCRON $^{6}$, cujos pesquisadores acreditam que mesmo quando não é possível modificar o curso da vida e da doença, é possivel que as pessoas nessa condição mantenham-se saudáveis. Resultados de estudos desse grupo de pesquisa mostram que maneiras saudáveis de enfrentar a condição crônica podem ser aprendidas por meio do processo educativo onde se exercita, principalmente, o compartilhar experiências em grupos de convivência (DIAS; TRENTINI; SILVA, 1995, TRENTINI; DIAS, 1997).

Os Grupos de Convivência como espaço para o desenvolvimento de educação em saúde, provocam uma educação participativa, com a intenção de reconstrução coletiva do viver cotidiano, problematizando as situações de vida. Isso requer que o profissional enfermeiro, que nesses grupos assume o papel de facilitador do processo ensinoaprendizagem, opte pelo compromisso com a educaçãosaúde, contemplando: a compreensão da situação, a perseguição de comportamentos saudáveis, a promoção de uma consciência social dos determinantes da saúde e a ativação do desenvolvimento de potencialidades e de personalidades (DIAS; TRENTINI; SILVA, 1995).

Interessados com a qualidade de vida das pessoas com IRC, resolvemos desenvolver uma pesquisa articulada com a prática assistencial em um grupo de convivência, que foi orientada pela seguinte questão:

Quais os elementos que influenciam a qualidade de vida de pessoas com Insuficiência Renal Crônica, em tratamento hemodialítico?

\section{METODOLOGIA}

Trata-se de uma pesquisa convergente assistencial, desenvolvida em um centro de tratamento hemodialítico da cidade de Florianópolis/SC. A pesquisa convergente assistencial tem a intencionalidade de encontrar soluções para problemas, realizar mudanças e introduzir inovações na situação social, incluindo um gesto de cuidar, porém não se consubstanciando como ato de cuidar; não se propõe a generalizações; segue normas de rigor científico; envolve os sujeitos pesquisados ativamente no processo de pesquisa; e reconhece os dados da prática como dados de pesquisa (TRENTINI;PAIM, 1999).

O estudo foi realizado durante as sessões de hemodiálise, e dele participaram seis pessoas com IRC em tratamento hemodialítico, que fazem parte de um grupo de convivência, quatro pesquisadores e uma bolsista de iniciação científica.

Os dados foram obtidos pela gravação em fitas cassete de treze encontros do grupo, realizados quinzenalmente no periodo de março a dezembro de 2000.

As temáticas desses encontros foram definidas pelo próprio grupo, incluindo: a Associação Catarinense de

6 Núcleo de Convivência em Situações Crônicas de Saúde. É um grupo de pesquisa especialmente interessado em desenvolver estudos com pessoas adultas com doenças crônicas e está vinculado ao Departamento de Enfermagem e ao Programa de Pós-Graduação em Enfermagem da Universidade Federal de Santa Catarina. 
Indivíduos com IRC como possibilidade de mais cidadania; a experiência de viver com IRC - da descoberta à situação atual; o que posso comer; o que mais eu posso fazer para cuidar da minha saúde - uso de terapias alternativas; o que é viver com IRC em tratamento hemodialítico; valores que orientam minha vida; transplante renal como possibilidade de uma vida de mais qualidade; superação de limites através de resignificação de experiências; transplante renal aspectos técnicos, legais e burocráticos; o que é qualidade de vida para pessoas com IRC; o que eu faço para viver bem com minha condição crônica de saúde.

Os dados foram analisados a partir da transcrição das fitas cassete, gravadas nos encontros, utilizando como referência à proposta de Trentini e Paim (1999), e seguiu os seguintes passos: 1) codificação dos dados: identificação dos trechos que abordavam a questão do viver com uma condição crônica de saúde e qualidade de vida; 2) formação das categorias: elaboradas a partir da identificação do conjunto de expressões que representavam os elementos que eram considerados como interferindo (favoravelmente ou não) na qualidade de vida; 3) interpretação dos dados: efetuada pela associação das informações contidas nas categorias e discutidas a partir do conceito de qualidade de vida estabelecido no projeto e na literatura abordando a temática.

Considerações éticas - Esta pesquisa foi aprovada pelo Comitê de Ética em Pesquisas com Seres Humanos da Universidade Federal de Santa Catarina, obedecendo a Resolução n. 196/96 do CNS/MS (BRASIL, 1996). Foi garantida a liberdade de participar ou não e de desistir a qualquer momento. Também foram assegurados o sigilo e o anonimato, utilizando pseudônimos para os integrantes do estudo. Obtivemos a assinatura do Termo de Consentimento Livre e Esclarecido de todos os participantes.

\section{RESULTADOS E DISCUSSÃO}

Decorrente do processo de análise dos dados foram identificadas quatro categorias que representam os elementos que os integrantes do estudo consideram na avaliação que fazem de sua qualidade de vida como interferindo na mesma, seja por possuírem esse elemento, seja por perceberem sua ausência ou limitação. São elas: assistência à saúde; processo de aceitação e de enfrentamento da condição de saúde; apoio recebido; e esperança num futuro melhor.

Essas categorias estão inter-relacionadas e, de maneira geral, representaram a avaliação que os integrantes do estudo fizeram sobre sua qualidade de vida. Falaram de uma vida onde existe qualidade, apesar de muitas vezes ser dificil perceber ou conquistar essa qualidade. Mesmo quando se referiram à falta de condições que favorecessem a qualidade de vida, essa era pensada como possível, como algo a ser conquistado. A seguir apresentamos as categorias constituidas:

\section{ASSISTÊNCIAÀ SAÚDE}

Essa categoria é composta por diferentes elementos: qualidade do serviço de assistência à saúde; acesso a informações, a medicamentos e a exames, tanto na perspectiva do reconhecimento da qualidade da assistência quanto na expectativa de melhor desenvolvimento da mesma.

Um dos aspectos da informação para o cuidado à saúde percebido, foi a inexistência de um sistema de informações adequado à população como forma de prevenção de doenças e promoção da saúde, que pode ser observado nos seguintes depoimentos:

Devia ser feito um informe para a população, para as pessoas que não tem insuficiência renal saberem o que pode causar. (...) Pouca gente sabe que a pressão alta estoura o rim. (Nereu)

O que falta para o brasileiro é educação, que é a base de tudo. (...) A prevenção deve ser feita como uma forma de alerta para a sociedade. (Júlio)

Nessas colocações há uma crítica implícita, reivindicando seus direitos como cidadãos, e que estão garantidos na legislação brasileira.

As informações prévias que tinham sobre hemodiálise, geralmente eram negativas ou e não correspondiam à realidade, evidenciando mais uma vez, a falta de informações da população sobre a IRC:

As outras pessoas têm uma visão diferente, é a visão que a gente tinha quando o médico me falou. É aquela visão de apavoro. (...) Falou em hemodiálise, eu queria morrer. (Júlio)

A gente na realidade não tem noção das coisas, nem sempre tem alguém que possa estar ali para te explicar, te ajudar. (Jonas)

Com relação ao suporte terapêutico, acreditavam no avanço da ciência como forma de melhorar o controle da IRC e suas conseqüências, porém o avanço científico não estava baseado em informações precisas, mas consistia da repetição de informações colocadas na mídia. A crença na ciência surgia nos momentos onde parecia não haver saída, e então colocavam como quase um "milagre" que viria para resolver seu problema, como mostra a seguinte fala:

Eu espero que aquele negócio de DNA resolva rápido e eles consigam fabricar um rim. (Júlio)

Outro aspecto da informação diz respeito a evolução da compreensão do tratamento e da doença, de modo a influenciar no processo de viver com sua condição de saúde, que passa ser vista como menos agressiva.

Situação semelhante foi observada por Gomes (1997), onde os pacientes diziam que a hemodiálise tornavase "suportável" e até "natural", depois de um certo tempo de tratamento, o que acreditamos tenha relação com a maior compreensão da situação.

Outro elemento que também interfere na qualidade de vida, vinculado à assistência de saúde, é a garantia do acesso gratuito a medicamentos (BRASIL, 2000), necessários à manutenção da vida, que nem sempre estão disponíveis nos serviços de saúde. O mesmo acontece com os exames que precisam ser realizados e que muitas vezes são adiados, suspensos ou marcados para datas que inviabilizam a continuidade do tratamento. Essa situação os deixa bastante ansiosos e interfere em seu bem-estar, influenciando a maneira como percebem sua qualidade de vida: 
Tem gente morrendo com recurso na mão. Cheio de gente morrendo porque são leigos. Novato do meu tipo assim, não tem direito. (Júlio)

Associação forte para lutar pelos direitos é uma forma de melhorar a qualidade de vida. Por exemplo, buscando exames e medicamentos necessários, tendo preferência no atendimento. Espero que no futuro a gente consiga mudar essa politica, pois temos falta de condições de pagar os medicamentos. (Jonas)

Esses depoimentos reforçam a percepção da contribuição que ações coletivas, através da associação, podem ter na assistência de saúde recebida, possibilitando melhores condições de lutar por seus direitos.

Nessa categoria, fica evidente o importante papel dos profissionais de saúde no desenvolvimento de uma assistência integral, onde o direito à informação precisa ser respeitado de modo a contribuir para uma melhor qualidade de vida. Isso inclui a "tradução" do conhecimento científico numa linguagem que possa ser compreendida por todos desde o início do tratamento, o que requer um cuidado especifico e individualizado. Nessa perspectiva, Lok (1996) destaca a importância do suporte dado pela enfermagem através de informações, análises críticas e discussões de alternativas de enfrentamento, como contribuindo para melhorar a qualidade de vida desses indivíduos.

\section{PROCESSO DE ACEITAÇÃO E DE ENFRENTAMENTO DA CONDIÇÃO DE SAÚDE}

A IRC causa um forte impacto na vida das pessoas, modificando-a no que diz respeito à condição física, ao cotidiano, ao trabalho, à alimentação e também aos valores que orientam as pessoas no seu processo de viver.

Essa perspectiva evidencia um processo psicossocial complexo, onde a aceitação da condição é colocada em destaque, no sentido de influenciar a maneira como a pessoa vai viver com a doença e o tratamento. No presente estudo, o processo de aceitação da condição e do tratamento, foi evidenciado como um dos elementos que interferem na qualidade de vida das pessoas, tendo sido identificados vários itens que participam desse processo, incluindo condições internas à própria pessoa e condições externas.

Como uma condição externa no processo de aceitação foi colocada a participação e o apoio da família e do profissional:

Eu acho que o problema maior do ser humano é talvez não ter a pessoa certa na hora certa para te acolher, para te ajudar a enfrentar algum problema. (Lorita)

Como condições internas para a aceitação teve destaque a manutenção da auto-imagem positiva e mudanças no papel desempenhado, seja na familia ou na sociedade, que incluiu perda dos sonhos, aspirações e estilo de vida, possivel perda das escolhas e opções, além do isolamento social que são expressos através dos seguintes relatos:

Eu costurava, bordava, pintava. Agora não posso mais nada disso. (Almerinda)

Você não pode transparecer a imagem de coitadinho.
Isso mostra que há uma luta sendo travada, no sentido de que percebem mudanças, mas que podem ou desejam superá-las.

Barbosa, Aguilar e Boemer (1999) citam que a maneira de reagir à doença difere de pessoa para pessoa, mas todos têm necessidade de reaprender a viver, e que isto é visto como indispensável. Encontramos esses sentimentos quando eles colocaram:

Eu acho que a gente deve ignorar algumas coisas e levar o resto adiante. Hoje eu sinto que a vida é tão minúscula, pequena, que tem coisas que a gente deve relevar, deixar passar e encarar o que é importante. (Nereu)

(...) Deus coloca uma coisinha para a gente aprender e começar a mudar e pensar melhor nas coisas que a gente faz.(...) As pessoas que não sofrem com a doença não dão valor a tantas coisas... Quando a gente tem a doença, a gente dá valor a tantas coisas. Isso é muito complexo, é outra vida, são outros valores. (Júlio)

Essa maneira de reagir frente à doença vai ao encontro do estudo de White e Grenyer (1999) que referem que os efeitos psicológicos relacionados à ansiedade, medo, perda da auto-imagem, percepção da doença e enfrentamento positivo, influenciam o tratamento. Assim, a maneira como enfrentam as mudanças decorrentes de sua doença e do tratamento, vai influenciar no processo de aceitação de sua condição, pois um enfrentamento mais efetivo, que inclui mudanças na perspectiva de vida, como a valorização do que é realmente importante, permite uma avaliação mais positiva de suas vidas, independente da condição de saúde que enfrentam.

Stork (1996) afirma que o processo de aceitação tem diferentes momentos: - primeiro, é a disposição de aprender, que exige tomar conhecimento de que não sabe; segundo, é a observação cuidadosa do que acontece ao meu redor, estar atento ao que ocorre; terceiro, inclui o respeito pela situação ou fato - a verdade; e, - quarto é o momento quando a aceitação se torna parte da própria pessoa, é a convicção de sua situação. Ainda para Stork (1996), a atitude ética a respeito da verdade, consiste em respeitá-la, enfrentá-la para reconhecê-la, mesmo que essa aceitação possa ser desconfortável ou complicada para a pessoa.

Assumir a condição não é um processo simples, pois envolve a culpa pela situação, o medo do desconhecido, a imaturidade, e a luta para conseguir aceitar sua condição, como mostram os depoimentos a seguir:

Eu tenho culpa de fazer hemodiálise porque eu tinha pressão alta. Tendo informação que a pressão alta afetava o rim, tendo a informação completa. Mas eu comia tudo errado eu também tive um pouco de culpa. (Nereu)

Todo mundo tem problemas na vida, eu tenho os meus problemas. Como eu era imaturo, talvez eu não tentei conseguir reduzir antes os meus problemas. (...) É dificil, até hoje é meio difícil. (Júlio)

A incorporação da doença e do tratamento, portanto, evidencia o quanto é difícil assumir a condição crônica no sentido apresentado por Stork (1996), quando a aceitação se torna parte da própria pessoa. Percebemos que a doença já é encarada, como integrando seu processo de viver, como 
expressam os depoimentos a seguir:

Ai o que eu fiz, incorporei a hemodiálise no meu dia a dia e pronto. Estou vivendo maravilhosamente bem. (...) Hoje eu já acostumei, levo a vida numa boa. (Nereu)

No começo mudou muito, mais agorajá me enturmei com o ruim, já virou rotina. (Júlio)

Este último depoimento mostra como ainda não é uma aceitação plena, mas apenas um "acostumar" com o que é ruim. A pessoa que fez esse depoimento demonstrou em vários outros momentos que tanto a doença quanto o tratamento ainda não eram "aceitos" mas apenas "tolerados". Como sintese do processo de aceitação da doença renal crônica e do tratamento hemodialítico, ressaltamos que a maioria dos participantes do estudo, aceitavam sua condição de saúde, tendo passado por períodos dificeis, de grande rejeição, de culpa, de lutas. Essa aceitação se evidenciou principalmente, na incorporação da doença e do tratamento no dia a dia e o reconhecimento de um viver harmônico com sua condição de saúde.

O processo de aceitação como interferindo na qualidade de vida, aponta alguns caminhos para o cuidado de enfermagem. É preciso compreender o momento vivido pelas pessoas e seus familiares, apoiar sem estabelecer condições, fornecer informações claras e consistentes de acordo com a necessidade e a capacidade de cada um, evidenciar as conquistas e avanços obtidos e mostrar a possibilidade de construção de um futuro com mais qualidade de vida. O envolvimento da familia nesse processo parece ser de grande importância, considerando a relevância dada pelos participantes para a ajuda recebida dos familiares.

É fundamental que os profissionais de saúde discutam as mudanças que estão acontecendo e/ou que irão acontecer, buscando alternativas que favoreçam um enfrentamento mais efetivo, de modo a que a qualidade de vida seja preservada.

\section{APOIORECEBIDO}

O apoio recebido da família e dos profissionais de saúde tem um papel determinante na avaliação que as pessoas fazem de sua qualidade de vida. Conforme relatam Barbosa, Aguilar e Boemer (1999, p. 300): "o fato de receber apoio das pessoas queridas fazo doente sentir-se melhor. $A$ doença de uma certa forma é também da família e, quando os familiares estão presentes, dando apoio constante, a dor do doente renal crônico é compartilhada, diluida".

Beard, citado por Barbosa, Aguilar e Boemer (1999), diz que o medo de viver uma vida insatisfatória como um doente crônico e incapacitado parece quase tão intolerável quanto o medo da morte iminente. Observou ainda, que os pacientes que se ajustavam melhor à doença e à incerteza de seu futuro, foram aqueles que tiveram relação intima com alguém que pudessem recorrer em ocasiões de tensão e desânimo.

Nos relatos das pessoas que integraram este estudo, há claramente o apoio recebido da familia:

Quem mais me ajuda é o meu marido, ele é tudo, é filho, é pai, é tudo. Estou casada há 30 anos, vivemos bem, ele é tudo. (Lorita)
Observou-se também que o apoio da equipe profissional foi um fator decisivo no primeiro momento, quando as pessoas ficaram sabendo que tinham que se submeter à hemodiálise:

O momento mais dificil foi quando o médico disse que eu tinha que fazer diálise, eu fiquei apavorado. Fui para casa chorando, apavorado, preocupado. Ai cheguei em casa contei para a mulher, ela chorou também, todo mundo chorando. Ai depois daquela choradeira, eu falei: 'Espere, também não vão chorar à toa'. Ai conversei com a enfermeira, ela me mostrou tudo, vim na sala de rim e comecei a fazer a diálise, ai não foi tão difícil. (Nereu)

Desse modo, receber apoio das pessoas que estão próximas, especialmente familiares e profissionais da saúde influencia na qualidade de vida de pessoas com insuficiência renal crônica em tratamento hemodialítico. Esse apoio é dado de diferentes maneiras, seja chorando junto, dando força, esclarecendo dúvidas ou discutindo opções de tratamento. Enfim, o estar próximo, parece o ponto mais importante nesse apoio.

\section{ESPERANÇA DE UM FUTURO MELHOR}

Na literatura, não há muitas referências de que modo as pessoas com problemas renais crônicos encaram seu futuro. São relatadas fases da adaptação ao tratamento hemodialítico, que vai desde um período inicial de "lua de mel", passando por um período de desencanto e, por fim, o período de adaptação em longo prazo, que ocorre quando as pessoas finalmente alcançam um nivel de aceitação de sua doença e de suas limitações.

Em nossa experiência com o grupo de pessoas com problemas renais, alguns relataram fé e esperança num futuro melhor, como mostra a seguinte colocação:

Espero me realizar profissionalmente, não quero insegurança. Quero estudar (...) Eu vou voltar a ter minha saúde boa para voltar a jogar futebol a perder o medo de fazer as coisas. (Júlio)

Um estudo desenvolvido por Gomes (1997) identificou que a "variável tempo em hemodiálise" era um importante fator, destacando que quanto maior o tempo mais a hemodiálise se tornava "suportável" e até "natural" e que as pessoas com menos tempo de hemodiálise demonstravam maior irritação, raiva, frustração e desconforto e um desejo de se acostumar com a hemodiálise de modo a acabar com essa angustia. Essa percepção de Gomes (1997) traz a esperança de um futuro mais sereno.

Nos relatos é evidenciado o otimismo quanto ao futuro e a necessidade de manter a esperança, que segundo Herth (1993), influencia positivamente o enfrentamento de situações dificeis, construindo a idéia de que o futuro poderá ser melhor. Crer na possibilidade de superar uma situação difícil impulsiona para uma vida de mais qualidade, pois favorece a sensação de alegria e permite acreditar na própria força interior. "Melhorar o nivel de esperança, é dar poder para controlar a própria vida e manter um sentimento de bemestar e confiança no futuro" (SILVA, 2001, p.163). Essa deve ser uma perspectiva importante para o profissional de saúde em relação ao cuidado das pessoas, de modo que mesmo quando ele considera as esperanças infundadas ou irreais, 
não pode se contrapor a esta percepção das pessoas. Precisa apoiá-las na superação de momentos difíceis e ajudá-las a concretizar suas expectativas quanto ao futuro.

\section{CONSIDERAÇÕES FINAIS}

Qualidade de vida é um conceito complexo que envolve vários elementos do processo de viver. Identificar quais são os elementos que pessoas com IRC, em tratamento hemodialítico, consideram como influenciando sua avaliação de qualidade de vida, foi um trabalho laborioso e que ainda apresenta lacunas, no sentido que acreditamos ter apenas iniciado a compreensão desse processo. Isso possibilitou um olhar mais amplo naquilo que valorizam, que modifica ou influencia suas vidas, que é desejado ou rejeitado por elas.

Foi possivel apreender que os elementos externos que influenciam na avaliação da qualidade de vida são a assistência recebida e o apoio recebido; os demais elementos (processo de aceitação e de enfrentamento da condição de saúde e esperança de um futuro melhor) são decorrentes de condições internas da pessoa, da satisfação e do bem-estar com seu processo de viver.

Assim, mesmo vivendo uma doença que tem repercussões importantes no seu bem-estar físico e com implicações para seu papel social, as pessoas se mostraram relativamente satisfeitas com sua qualidade de vida, nos elementos que identificarmos como integrando a avaliação que fazem da mesma.

\section{REFERÊNCIAS}

BARBOSA, J. C.; AGUILAR, O. M.; BOEMER, M. R. O significado de conviver com a insuficiência renal crônica. Rev. Bras. Enferm., Brasilia, v. 52, n. 2, p. 293-302, abr./jun. 1999.

BRASIL, Ministério da Saúde. Portaria $n^{\circ} 82$, de 03 de janeiro de 2000. Estabelece o regulamento Técnico para o funcionamento dos serviços de diálise e as normas para cadastramento destes junto ao Sistema Único de Saúde. Disponivel em: http:/ /www.saude.gov.br/mweb/portarias. Acesso em: 21 de fev. 2000.

BRASIL, Conselho Nacional de Saúde. Resolução $n^{\circ}$ 196, de 10 de outubro de 1996. Aprova diretrizes e normas regulamentadoras de pesquisas envolvendo seres humanos.

CESARINO, C. B.; CASAGRANDE, L. D. R. Paciente com insuficiência renal crônica em tratamento hemodialítico: atividade educativa do enfermeiro. Rev. Lat-Am. Enfermagem, Ribeirão Preto, v. 6, n. 4, p. 31-40, out. 1998.

DIAS, L. P. M.; TRENTINI, M.; SILVA, D. M. G. V. da. Grupos de Convivência: uma alternativa instrumental para a prática da enfermagem. Rev. Texto e Contexto - Enfermagem, Florianópolis, v.4, n. 1, p. 83-92, jan./jun. 1995.

GOMES, C. M. A. Descrição da qualidade de vida dos pacientes em hemodiálise. Revista Médica de Minas Gerais. Belo Horizonte, v. 7, n. 2/4, p. 60-63, abr./dez. 1997.

GERHARDT, U. Qualitative reseach on chronic illnmess: the isue and story. Soc. Sci. Med, Great Britain, v.30, n.11, p.1149-1159, 1990.

HERTH, K. Hope in the caregiver of terminaly ill people. J. Adv. Nurs., [s. I.], v. 18, p. 538-548, 1993.

LIMA, A. F. C.; GUALDA, D, M. R. Reflexão sobre a qualidade de vida do cliente renal crônico submetido a hemodiálise. Nursing, p. 20-30, nov. 2000.

LOK, P. Stressors, coping mechanisms and quality of life among dialysis patients in Australia. J. Adv. Nurs., v. 23, p. 873-881, 1996.

NORDENFELT, L. Concepts and measurement of quality of life in health care. Netherlands: Kluwer, 1994.

SILVA, D. M. G. V. da. Narrativas do viver com diabetes mellitus: experiências pessoais e culturais. Florianópolis: Programa de Pós-Graduação em Enfermagem/UFSC, 2001.

STORK, R. Y. Fundamentos de Antropologia: un ideal de la experiencia humana. 2. ed. Navarra: Line Grafic, 1996.

TRENTINI, M.; PAIM, L. Pesquisa em Enfermagem: uma modalidade convergente-assistencial. Florianópolis: Editora da UFSC, 1999. Série Enfermagem.

TRENTINI, M.; DIAS, L. P. M. Ser-mais - uma possibilidade de promover saúde pela prática educativa. Revista Acta Paulista, São Paulo, v. 2, n. 2, p. 20-24, 1997.

WHITE, Y; GRENYER, B. F. S. The biopsychosocial impact of end-stage renal disease: the experience of dialysis patients and their partners. J. Adv. Nurs., v. 30, n. 6, p. 1312-1320, 1999. 